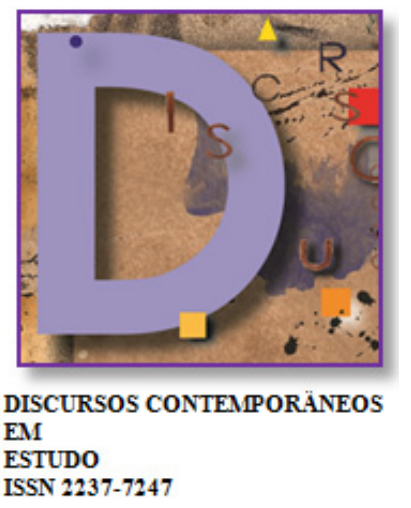

\title{
ENSINO DO PORTUGUÊS BASEADO NOS GÊNEROS
}

\author{
Edna Cristina Muniz da Silva ${ }^{1}$
}

Este trabalho é o resultado de uma pesquisa realizada com turmas dos últimos ciclos do ensino fundamental na área de Língua Portuguesa em uma escola militar em BrasíliaDF. Meu objetivo é mostrar que os gêneros ${ }^{2}$ devem constituir o centro para o ensino de letramentos, baseando-me em teorias críticas e funcionais para o estudo da linguagem. Para compreender a relação entre gêneros e práticas de letramento no contexto desta pesquisa, apoio-me na articulação de três abordagens teóricas: (1) Análise de Discurso Crítica (FAIRCLOUGH, 1992/2001; CHOULIARAKI; FAIRCLOUGH, 1999; FAIRCLOUGH, 2003); (2) Abordagens teóricas sobre os gêneros (BAKHTIN, 2000; HALLIDAY; HASAN, 1991; EGGINS; MARTIN, 2000; EGGINS, 2004; HALLIDAY; MATTHIESSEN, 2004). Nesta pesquisa, é investigado como os textos são estudados nas aulas de Língua Portuguesa e em que medida o ensino da escrita contribui para que os estudantes se apropriem dos gêneros como recurso para agirem e para interagirem em diversos domínios sociais. Esta pesquisa indica que o ensino de letramentos deve se apoiar no estudo dos gêneros. Uma pedagogia de ensino de letramentos baseada nos gêneros permite o reconhecimento da diversidade do contexto cultural que envolve os textos, conforme as práticas sociais que os demandam. A consciência dos gêneros e das práticas de letramento em que se realizam efetivamente contribui para que noss@s estudantes desenvolvam capacidades para agirem e para interagirem discursivamente em diferentes domínios e práticas sociais.

Palavras-chave: Gêneros. Práticas de Letramento. Ensino de Gramática. Aulas de Língua Portuguesa.

\footnotetext{
${ }^{1}$ Graduação em Letras-Licenciatura em Língua Portuguesa e Literatura pela Universidade de Brasília (1987). Mestrado em Linguística pela Universidade de Brasília (1995) com o trabalho "A coesão em textos produzidos por alfabetizandos adultos". Estágio de doutorado na Faculdade de Letras da Universidade de Lisboa (2005-2006). Doutorado em Linguística pela Universidade de Brasília (2007) com o trabalho "Gêneros e práticas de letramento no Ensino Fundamental". E professora adjunta do Departamento de Linguística, Português e Línguas Clássicas da Universidade de Brasília. Desenvolve pesquisa na área de Linguagem e Sociedade, linha de pesquisa Discursos, Representações Sociais e Textos, com ênfase em Análise de Discurso Crítica e Linguística Sistêmico-Funcional, abordagens teóricas sobre gêneros e letramentos. Atuou como coordenadora do Curso de Letras a Distância (UAB/ UnB) de outubro/2008 a fevereiro/2011. É membro da comissão editorial de Cadernos de Linguagem e Sociedade (Núcleo de Estudos de Linguagem e Sociedade - NELIS/UnB) e da revista Discursos Contemporâneos em Estudo (Centro de Pesquisas em Análise de Discurso Crítica-CEPADIC/UnB). Está realizando pesquisa de pós-doutorado na área da Linguística Sistêmico-Funcional. É Coordenadora de Graduação do Curso de Licenciatura em LetrasPortuguês (noturno).

${ }^{2}$ Neste trabalho, emprego o termo "gêneros" como o uso da linguagem nas interações sociais.
} 


\section{Introdução}

A principal motivação para estudar a relação entre os gêneros e as práticas de letramento no ensino, no contexto das aulas de Língua Portuguesa, foi inspirada na minha experiência como professora de Português, em turmas de $5^{\mathrm{a}}$ a $8^{\mathrm{a}}$ série. Por mais que eu me esforçasse, a experiência era frustrante porque os alunos efetivamente não gostavam de ler nem de escrever e, quando o faziam, o resultado era ruim: textos precários quanto à estrutura, ao desenvolvimento do tema e ao uso das estruturas linguísticas, além de serem descontextualizados.

Entendo que os gêneros devem constituir a base para o ensino dos letramentos ${ }^{3}$ nas aulas de Língua Portuguesa no ensino fundamental (de $5^{\mathrm{a}}$ a $8^{\mathrm{a}}$ série), tendo em vista que a falta de domínio d@s estudantes ${ }^{4}$ na leitura e na escrita deve-se ao ensino de língua orientado pela perspectiva da gramática tradicional e ao tratamento dos textos como objetos, sem considerar as práticas sociais em que são produzidos. Os gêneros são modos de (inter)agir discursivamente no curso das práticas sociais e materializam-se semioticamente nos textos, daí a sua relevância para o ensino dos letramentos múltiplos.

O ensino da leitura e da escrita com base nos gêneros está no centro das orientações dos Parâmetros Curriculares Nacionais (PCN) para o ensino da Língua Portuguesa nos últimos ciclos do ensino fundamental, que apontam para a necessidade de uma didática da língua que reconheça a expansão do uso da escrita na sociedade contemporânea. A evolução dos meios de comunicação eletrônicos criou novas demandas sociais que moldam gêneros e letramentos ao articularem diversos elementos semióticos na criação de textos. São novas formas de leitura e de escrita que estão sendo vivenciadas, as quais a escola não deve ignorar, porque estão promovendo uma mudança profunda nas práticas de letramento ${ }^{5}$ que associam três tipos de escrita: manuscrito, impresso e eletrônico. Entendo que o texto manuscrito está cada vez menos sendo utilizado, principalmente pel@s noss@s estudantes, que, na escola onde esta pesquisa foi realizada, têm acesso à rede mundial de computadores e aos letramentos digitais, tendo como consequência a resistência dess@s estudantes em participar dos eventos de letramento ${ }^{6}$ das aulas.

O estudo dos gêneros, portanto, associado a práticas de letramento que levem em conta a diversidade de contextos culturais e sociais de domínio público, adquire relevância nas aulas de Língua Portuguesa porque pode contribuir para melhorar o desempenho d@s estudantes na leitura e na escrita, além de instrumentalizá-los com conhecimento especializado sobre a relação entre a linguagem e as práticas sociais ${ }^{7}$. Nesta pesquisa, o propósito é verificar como

${ }_{3}^{3}$ Letramento é um conjunto de práticas sociais inferidas a partir de eventos que são mediados por textos escritos (BARTON; HAMILTON, 1998). Neste artigo, utilizo o termo "letramento" para referir-me à leitura e à escrita.

${ }^{4} \mathrm{O}$ símbolo@é utilizado por motivo de economia linguística na designação simultânea do gênero feminino e do masculino nas referências a estudantes e adocentes e, assim, evitou a ocorrência de sucessivos o/a.

${ }_{5}^{5}$ Práticas de letramento é um conceito que se refere aos modos como são construídos os significados dos textos escritos em contextos culturais e sociais (STREET, 2000; BARTON; HAMILTON, 1998).

${ }^{6}$ Eventos de letramento são situações particulares, observáveis, que envolvem a leitura e/ou a escrita de textos (STREET, 2000; BARTON; HAMILTON, 1998).

${ }^{7}$ A prática social refere-se à dimensão econômica, política, ideológica e cultural da estrutura social, podendo relacionar-se ao discurso nos eventos sociais (FAIRCLOUGH, 1992/ 2001). 
os textos são estudados nas aulas e em que medida o ensino da escrita contribui para que @ s estudantes apropriem-se dos gêneros como recursos para agirem e para interagirem em diversos domínios sociais.

O enfoque teórico utilizado justifica-se em razão das radicais transformações sociais, econômicas e políticas (também denominadas de globalização, de modernidade tardia ou pós-modernidade, de sociedade da informação, de economia do conhecimento, de cultura do consumo), que são parcialmente realizadas por meio do discurso ${ }^{8}$. No contexto social contemporâneo, em que a expansão dos meios de comunicação eletrônicos ampliou a utilização de diferentes gêneros nas instituições sociais, torna-se fundamental uma reflexão sobre o ensino de leitura e de escrita nas aulas de Língua Portuguesa, disciplina oficialmente responsável por ensinar a ler e a escrever.

As aulas de Língua Portuguesa foram escolhidas como alvo desta investigação porque constituem um espaço em que professores e estudantes falam, leem e escrevem sobre diversos assuntos (e não necessariamente sobre língua e textos), cujos significados são construídos pela leitura e pela escrita. Esses sentidos tanto contribuem para o posicionamento de estudantes e de professores diante das práticas de letramento escolares quanto podem ser contestados pelos estudantes, que participam de outras práticas discursivas na família e na comunidade.

A apropriação da função social das práticas de leitura e de escrita é primordial para que @ s estudantes questionem os significados construídos na escola, porque estes influenciam o modo como nos representamos e como representamos os outros. Os professores de Língua Portuguesa podem mostrar aos alunos como agir no mundo por meio dos gêneros associados a práticas de letramento contextualizadas.

As práticas de letramento em uma sala de aula a caracterizam como uma comunidade de estudantes e de professores que podem utilizar diversos gêneros, motivados, segundo Halliday e Hasan (1991), por três objetivos: aprendizagem e/ou ampliação do repertório dos gêneros dos estudantes; ensino e conscientização dos gêneros; e ensino por meio dos gêneros. Os gêneros podem ser utilizados como ferramentas culturais para estabelecer, para sustentar, para expandir e para resistir a ideias, a informações e a conhecimentos. Nesse sentido, o estudo dos gêneros associado a práticas de letramentos propicia o desenvolvimento da consciência d@s estudantes para o papel ideológico desempenhado pelos textos nas relações sociais, como instrumentos para ação e para interação dos sujeitos nos diversos domínios sociais.

Os gêneros constituem uma categoria de estudo muito útil para o ensino de letramentos. O conceito de gênero de Bakhtin (2000, p. 279) tem servido como base para o desenvolvimento de várias abordagens teóricas em diversos campos, como a literatura, a retórica, a mídia e a linguística. As abordagens de gênero adotadas nesta pesquisa aproximam-se da Análise de Discurso Crítica (FAIRCLOUGH 1989, 1995, 2003), dos Novos Estudos do Letramento (STREET 1984, 1993, 1995; BARTON; HAMILTON,

\footnotetext{
${ }^{8}$ Neste trabalho, o termo "discurso" é utilizado no sentido de linguagem como prática social. O discurso é um modo de ação e de representação, que se relaciona dialeticamente com as práticas e com as estruturas sociais: tanto é moldado por essas últimas, como contribui para a constituição das dimensões da estrutura social. Em outras palavras, o discurso é socialmente constitutivo (FAIRCLOUGH, 1992/2001, p. 91).
} 
1998; BARTON; IVANIC, 1991; BARTON; HAMILTON; IVANIC, 2000) e da perspectiva sistêmico-funcional (EGGINS; MARTIN, 1998; EGGINS, 2004; HALLIDAY; HASAN, 1991 HALLIDAY; MATTHIESSEN, 2004), em que o texto é considerado em seus aspectos oral, escrito e visual.

O conceito de discurso de Fairclough $(1995$, p. 7) - para quem discurso é o uso de linguagem como uma forma de prática social e análise de discurso é análise de como os textos funcionam na prática sociocultural - corrobora sua aplicação na abordagem de gêneros adotada neste trabalho porque inclui a análise da forma, da estrutura e da organização textual nos níveis fonológicos, gramaticais e lexicais, além da análise das estruturas textuais e genéricas. Do mesmo modo, a concepção de letramento como prática social (STREET, 1985; BARTON; HAMILTON; IVANIC, 2000) é basilar a este trabalho porque situa a escrita e o seu significado dentro das práticas sociais e de discursos específicos nas instituições e nas relações de poder que os sustentam.

\section{Pressupostos teóricos}

\section{Análise de Discurso Crítica}

Ao apresentar o discurso como prática social, Fairclough (1992/2001) situa o discurso em relação à ideologia e ao poder, entendendo que a ideologia tem existência material nas práticas institucionais. A ideologia implica um conjunto de significações/construções da realidade (o mundo físico, as relações sociais, as identidades sociais), que contribuem para a produção, a reprodução ou a transformação das relações de dominação. Ou seja, determinados usos da linguagem e de outras formas simbólicas são ideológicos, pois servem em circunstâncias específicas para estabelecer ou para manter relações de dominação.

Tradicionalmente, as atividades de leitura e de escrita em aulas de Língua Portuguesa têm-se restringido às formas linguísticas prestigiadas socialmente devido aos gêneros privilegiados na escola, cujo ensino adota a perspectiva dos grupos sociais dominantes, promovendo cada vez mais a exclusão social e cultural. Os professores têm ignorado os gêneros que constituem as práticas dos diferentes domínios e instituições sociais. Um ensino de Língua Portuguesa emancipador deve levar em conta um contexto de práticas sociais nos níveis local e global, que focalize modos de representação variados, associados a tecnologias da informação e de multimídias, que pressupõem o controle de formas de representação cada vez mais significativas, como as imagens e sua ligação com a escrita, por exemplo.

De acordo com a Análise de Discurso Crítica, os gêneros são considerados sob uma perspectiva histórica e cultural como configurações textuais ligadas a processos particulares de produção, de distribuição e de consumo, devendo ser estudados como formas retóricas vinculadas a situações sociais que demandam respostas típicas, em uma determinada interação social, a tipos específicos de atividades (FAIRCLOUGH, 1992/2001, 2003). Os gêneros são lugares de tensão entre estabilidade e mudança, uma vez que "gêneros existentes mudam a partir de modificações na situação social na qual exercem uma função ou novos gêneros 
podem surgir a partir de transformações ostensivas daqueles já existentes" (PAGANO, 2001, p. 87). Isso significa que os textos, na medida em que constituem gêneros específicos, também estão permanentemente ativando outros gêneros.

O conceito de gêneros exerce papel relevante para a elaboração de didáticas de letramento engajadas na conscientização dos professores sobre as práticas sociais que privilegiam determinados gêneros para estabelecer e para sustentar relações de dominação e, dessa forma, exercer controle social. Na medida em que a possibilidade de transformação textual, aspecto constitutivo do gênero, caracteriza um processo dinâmico de transformação social, os modelos que caracterizam a construção de novos textos nunca estão acabados, estando sempre sujeitos a novas incorporações que podem gerar mudança e contribuir para a constituição de identidades.

\section{Abordagens sobre os gêneros}

Gêneros referem-se a como os textos se estruturam tipicamente segundo formas recorrentes, híbridas e convencionais, permitindo que os indivíduos estabeleçam relações entre si e façam coisas juntos em contextos sociais e culturais específicos. O conceito de gênero, tradicionalmente construído no campo da retórica e da literatura, tem-se tornado um pressuposto teórico para análise da forma e da função dos discursos institucionais e uma ferramenta para o desenvolvimento do ensino da leitura e da escrita.

Para Bakhtin (2000), cada esfera da comunicação humana apresenta um repertório de gêneros, orais e escritos, que se diferenciam à medida que determinada esfera se desenvolve e torna-se mais complexa. Bakhtin fez distinção entre gêneros primários e secundários. Os gêneros primários relacionam-se diretamente à comunicação verbal cotidiana, como os diálogos, por exemplo, e compõem os gêneros secundários, que surgem nas esferas de comunicação mais complexas e desenvolvidas, sendo fundamentalmente escritos, como novelas, artigos científicos, romances. Os gêneros não são simplesmente um conjunto de regras e de convenções, mas modos de entender a realidade e de interpretar o mundo, constituídos de três elementos básicos - conteúdo temático, estilo e construção composicional - que se imbricam no texto em uma configuração determinada pelas especificidades das práticas sociais.

As pessoas participam, no seu dia a dia, de redes de práticas sociais que são mediadas pela linguagem e que articulam diversos elementos das estruturas sociais, como as relações sociais, as pessoas e suas crenças, atitudes e história, o mundo material, o discurso. De acordo com Fairclough (2003), o discurso pode figurar de três maneiras nas práticas sociais: (a) como parte de uma atividade social (por exemplo, para exercer a atividade de venda, o vendedor emprega a linguagem de uma maneira particular); (b) como modo de representação da realidade, em que os atores sociais se posicionam diferentemente ao produzirem representações de outras práticas e suas próprias representações no curso das atividades sociais; (c) como modo de ser na constituição de identidades sociais.

Os gêneros, modos de interagir discursivamente no curso das práticas sociais, materializam-se linguisticamente nos textos. De acordo com Halliday e Hasan (1991, p. 10), 
o texto é uma unidade semântica que se realiza linguisticamente em um contexto situacional cujos sentidos são codificados por palavras, por frases e por estruturas. Ou seja, o texto é produto de um processo contínuo de escolha de significados que estão disponíveis no contexto sociocultural e são representados pelo sistema linguístico.

Fairclough (2003) entende como gênero o aspecto discursivo convencional de modos de agir e de interagir estáveis, definidos pelas práticas sociais e suas inter-relações no curso dos eventos sociais. Por serem construídos socialmente, fornecem os sinais para que os sujeitos interpretem as particularidades de uma interação comunicativa específica. Todos os membros de uma comunidade se apropriam diferentemente - no tempo e no espaço - dos diversos gêneros e de seus significados, que são construídos e modificados coletivamente o tempo todo no processo contínuo de interação e de colaboração em práticas sociais compartilhadas. Isso ocorre porque parte da ação social implícita no uso ou no reconhecimento de um gênero é política, dado que os gêneros não são utilizados igualmente por todas as pessoas, mesmo que participem da mesma comunidade discursiva (por exemplo, não são todas as pessoas que produzem textos - e mesmo assim, quando produzem, são textos de gêneros específicos e não todos; da mesma forma, também não são todos que leem textos), porque as formas de interação são constituídas por tipos particulares de relações sociais entre os agentes da interação, as quais se diferenciam conforme o poder e a solidariedade (FAIRCLOUGH, 2003).

Os gêneros variam quanto à sua estabilização, fixidez e homogeneização. Alguns gêneros - como o artigo acadêmico - são ritualizados. Outros são completamente variáveis - como os textos publicitários. Na época atual, em que passamos por um período de transformações sociais rápidas e profundas, há uma tensão entre a estabilização, a força de consolidação da nova ordem social e o fluxo das mudanças. As transformações sociais decorrentes do processo de globalização produzem mudanças nas inter-relações das práticas sociais e, consequentemente, mudanças nas formas de ação e de interação que levam a mudanças nos gêneros. Por apresentarem diferentes níveis de abstração e de percepção decorrentes do dinamismo das práticas sociais, os gêneros não apresentam terminologia estável, isto é, em algumas situações diferentes, é possível que haja a mesma denominação para gêneros distintos. Nesse caso, cabe verificar o que ocorre efetivamente nas práticas quanto à variedade de atividades que um gênero pode contemplar. Texto e contexto se associam na construção dos sentidos do que é dito ou escrito nos ambientes sociais em que se desenvolvem e são interpretados (HALLIDAY; HASAN, 1991, p. 5). Nesse sentido, toda língua é compreendida em seu contexto de situação e de cultura porque os textos que produzimos sempre desempenham algum papel em algum contexto. Os textos que compartilham o mesmo propósito social em uma cultura também compartilham o mesmo padrão estrutural, ou o mesmo gênero. Investigar os padrões estruturais de diferentes gêneros significa captar a riqueza do repertório dos elementos textuais, que constituem a base para a elaboração de textos coerentes, sensíveis às complexas demandas culturais.

\section{Os gêneros e o ensino da gramática}

De acordo com os relatos das professoras que participaram da pesquisa, percebe-se que as atividades de gramática propostas em sala de aula não se conjugam com leitura e com produção de textos, que são situações significativas de letramento em que a gramática 
da língua provê as regras para composição dos textos. Também o trabalho com a gramática não leva em consideração a variação da língua em uso nos diferentes contextos sociais. Uma das professoras disse que @s estudantes reclamam das regras da gramática, mas querem aulas em que se ensinem as regras. Isso evidencia que @s estudantes estão reproduzindo o comportamento das próprias professoras, que lhes transmitem regras, rótulos e nomenclaturas gramaticais em grande parte do tempo das aulas, sem reflexão sobre que pessoas e que textos utilizam essas regras. Vejam-se os seguintes fragmentos do relato de uma das professoras:

\begin{abstract}
Quanto ao ensino de língua, é um desafio porque os alunos dizem: 'professora, eu já nasço falando'. Mas você deve diferenciar, deve saber quando deve falar de acordo com a gramática, quando não deve... Quando você pode incluir uma expressão, que antes não existia... Só que muitas vezes eles não entendem isso. Eles acham que a Língua Portuguesa é só regra, que eles têm que decorar, como se fosse matemática. Se você tenta fazer algo diferente de passar regra no quadro, eles não conseguem, assim... eles não querem pegar [...]. Igual o exercício de revisão que nós estávamos passando, né? Um exercício abordando todos os conteúdos... Eles não querem... Eles querem que você dê aquela aula ensinando regras. E eles reclamam das regras, só que eles só querem regras. [...] Eles fazem essa distinção, de Língua Portuguesa, assim, do português mesmo gramática, e de quando a gente pede redação, é... produção de texto... Eles veem essa diferença. Eles falam: "ah, produção de texto não é português". Eles têm essa mania de diferenciar aula de gramática e aula de textos. (Sabrina) (informação verbal).
\end{abstract}

Neves (2006, p. 114) nos mostra que a sociedade está viciada em uma tradição de ensino de língua em que a sistematização das regras gramaticais, a exposição de seus conceitos, as definições, os exemplos e a realização mecânica de exercícios contribuem para o resgate do que é considerado linguagem culta ou padrão. No entanto, o resultado dessa prática é que, de fato, @s estudantes não veem sentido no estudo dessas regras e não sabem como aplicá-las em situações concretas de letramento, conforme os relatos das professoras que participaram desta pesquisa, visto que o ensino da gramática se reduz à exposição da nomenclatura da gramática tradicional.

Os trechos a seguir mostram que a professora demonstra não saber o que fazer diante do ensino mecânico de gramática. Em sua fala, deixa transparecer que fatores sociais, como o vestibular, determinam que o ensino de gramática seja da forma como é realizado. Entretanto, ao mesmo tempo, ela tem preocupação com a imagem dos professores de língua que dão aulas de gramática tradicional, revelando que ela própria não vê sentido no ensino descontextualizado de regras gramaticais:

Mas eles estão distantes! Você tá falando de sujeito e predicado e eles tão viajando num show que vai acontecer sábado! Numa festa! E aí? Fazer o quê? Você precisa passar o conteúdo [...]. Nós saímos da faculdade com 
esse intuito. Lá eu aprendi a passar o conteúdo! Mas eu chego aqui, eu encontro adolescente que tem mil problemas e aí? O que fazer? [...] Porque a sociedade cobra o conteúdo. O vestibular cobra o menino saber e tirar dez, fechando a prova. E ai? Mas existe o lado humano. Existe aquela criança que não é uma máquina. E onde ficamos nós, profissionais, quanto a isso aí? (Esmeralda) (informação verbal)

Neves (2006, p. 115-116) chama a atenção para o caráter ritual do ensino da gramática tradicional nas escolas, baseado na rotulação e na classificação das entidades gramaticais; na prévia definição das entidades como algo acabado, inequívoco e absoluto; na taxonomia de categorias alheias aos usos e às funções da língua na construção dos significados do discurso; nos limites da estrutura da oração; enfim, na falta de reflexão sobre o uso da linguagem e na falta de compreensão de que a heterogeneidade é constitutiva da linguagem, pois a língua é um sistema eminentemente variável.

A falta da dimensão reflexiva sobre o ensino da gramática tradicional é visível no relato das professoras. Uma delas mencionou o trabalho da gramática com o texto para se referir à prática de análise sintática em fragmentos de texto, em que @s estudantes devem identificar, por exemplo, os sujeitos, os adjuntos adnominais e o predicado. Essa prática ignora o funcionamento da linguagem, o enquadramento dos textos escritos em gêneros, as configurações discursivas e linguísticas moldadas pelos propósitos dos diversos contextos sociais que os usos da escrita apresentam, em que a linguagem é um meio para a realização de atividades e de eventos (CHOULIARAKI; FAIRCLOUGH, 1999):

Você chega na sala de aula, eu tô dando regras de gramática. Ele (@ estudante) precisa dessas regras, mas faça com que ele entenda isso... É difícil. Pra nós (professoras), é difícil. (Esmeralda) (informação verbal).

[...] Ás vezes, eu tô ensinando: nesse caso aqui, o verbo é intransitivo. Por exemplo: "Esse pincel está aqui". Predominantemente, na maioria das vezes, o verbo "estar" fica instransitivo. Certo? Então, eles ficam: mas aí, toda vez... Eles querem criar regras. (Vanessa) (informação verbal).

Outra dificuldade que eu vejo também é quando eles [...] a gente vai trabalhar gramática com texto. Aí, geralmente você coloca um texto assim: vamos tirar os sujeitos do texto. Aí, eles falam: "professora, mas pra que você tá colocando texto? Coloca frase!". Realmente, eu vejo assim: na frase, é mais fácil você separar sujeito e predicado do que no texto. Parece que eles têm preguiça $[. .$.$] de ler um texto todinho pra tá interpretando,$ pra tá analisando... E é muito mais fácil realmente a gente trabalhar com a frase, separar o sujeito e o predicado de uma frase, do que de um texto todo. Eles... parece que se perdem um pouco. (Marta) (informação verbal). 
O excerto acima demonstra que o ensino de língua pautado na análise de frases e de orações recortadas de textos e de falas extraídos de seus contextos sociais de uso é sem propósito, usando os termos empregados por Neves (2006, p. 125), visto que "a gramática de uma língua em funcionamento não se faz de regras absolutas, com condições autônomas de aplicação" (NEVES, 2006, p. 128). Neves propõe que o ensino da gramática deve conduzir à reflexão sobre o funcionamento da linguagem e que estudar gramática significa o exercício da língua em uso, como em contextos socioculturais em que as pessoas leem e escrevem.

Uma professora relatou que seus estudantes fazem distinção entre o que seja aula de Língua Portuguesa e aula de produção de texto. Os estudantes não percebem que a gramática da língua provê as regras para a produção de textos e que os sentidos são construídos e negociados nas interações sociais. Isso ocorre porque há um entendimento generalizado, baseado na perspectiva estruturalista, de que a gramática da língua é uma dimensão separada do contexto sociohistórico que determina como os textos são produzidos nas práticas sociais:

Eles fazem essa distinção, de Língua Portuguesa, assim, do português... mesmo gramática, e de quando a gente pede a redação, é... produção de texto... eles veem essa diferença. Eles falam: "ah, produção de texto não é português". Eles têm essa mania de diferenciar aula de gramática e aula de textos! (Sabrina) (informação verbal).

A língua é um recurso de que nos valemos para construir os sentidos dos textos que produzimos, lemos e ouvimos. Quando falam, leem e escrevem, as pessoas produzem textos. De acordo com a abordagem sistêmico-funcional, o texto é definido como uma instância de língua que realiza algo em um contexto de situação, seja na forma escrita, seja na forma falada ou combinando múltiplas semioses (HALLIDAY; MATTHIESSEN, 2004, p. 3-5). Entender o texto da perspectiva sistêmico-funcional implica relacioná-lo ao seu contexto de cultura e de situação e ver a linguagem como um sistema semiótico que é estruturado léxicogramaticalmente. $\mathrm{O}$ texto medeia a interação dos participantes - escritores e leitores - em um contexto de situação, encapsulado no próprio texto mediante uma relação sistemática entre o contexto social e a organização funcional da linguagem.

As aulas observadas evidenciam que@s estudantes reagem mecanicamente quando são solicitados a identificarem os termos da oração. No contexto de situação dessas aulas, geralmente a professora propõe exercícios de gramática, em que @s estudantes devem apenas identificar a classificação de termos da oração. Trata-se de exercícios que foram passados para serem feitos em casa e, na aula, a professora os corrige.

Essas aulas constituem, então, eventos de letramento que se fundamentam basicamente na descrição gramatical dos elementos constituintes da oração, o que é entendido pela sociedade como uma prática que contribui para a aprendizagem dos letramentos, embora os resultados escolares demonstrem o contrário. Isto é,@s estudantes têm bastante dificuldade para a leitura e para a produção de textos escritos porque não reconhecem que as estruturas léxico-gramaticais são instrumentos para expressar os significados funcionais de um texto e dos gêneros que realiza. 
No exemplo a seguir, extraído de uma aula de Língua Portuguesa, a professora declara que @ s estudantes sempre querem criar regras com base nos conteúdos gramaticais apresentados. Ao explicar o verbo intransitivo e o verbo de ligação, a professora focaliza apenas o aspecto formal sem reflexão sobre que significados o emprego dessas estruturas constroem.

\begin{abstract}
Agora, falando de aula de gramática, se é que pode falar assim, que não seja produção de texto, é... às vezes eu tô ensinando: "Nesse caso aqui, o verbo é intransitivo". Por exemplo, "Esse pincel está aqui". Predominantemente, na maioria das vezes, o verbo "estar" é o quê? Eles dizem: é verbo de ligação. Isso eles já entenderam bem. Aí... mas vamos ver um caso que não é? "Esse pincel está aqui". Aqui é lugar. Então, "estar fica intransitivo. Certo?" Então, eles ficam: mas aí, toda vez... Aí, eles querem criar regras. "Toda vez que terminar com letra $o$ vai ser isso." Aí, na falta de regras... Quando a gente fala assim: "Não pode generalizar, depende do contexto, tal...". Quando você fala isso, eles: "Então, toda vez que terminar na letra $o$ vai ser o caso" tal.... Eles mesmos querem criar regras. (Marta) (informação verbal).
\end{abstract}

As considerações da professora no trecho acima evidenciam uma visão de aprendizagem que desconsidera a intuição d@s alun@s sobre a gramática dos textos, quando ela diz que eles querem criar regras com base em generalizações que, segundo ela, não procedem. No seu discurso, a professora pratica as generalizações descontextualizadas, mas prega a contextualização das regras gramaticais.

No trecho seguinte, a professora acredita que usar os temas do cotidiano que agradam @ s estudantes é o caminho para que se interessem pelo descontextualizado estudo de conteúdos gramaticais. A escolha de temas triviais como instrumento para análise sintática tem constituído uma representação ideológica do uso da língua, porque há uma aparente busca de contextualização do estudo gramatical, embora prevaleça a manutenção das descrições gramaticais sem preocupação com os significados que as escolhas léxico-gramaticais produzem no discurso. O foco do estudo da língua permanece o mesmo: a análise sintática de frases dissociadas dos gêneros que as produziram ou que podem produzi-las.

Mas, eu, vendo ontem, que eles tavam falando... eu acho que eles ficaram muito eufóricos por causa da festa sábado. Então, ontem eu tive que dar uma revisão, e o assunto era a festa. Eu aproveitei o assunto "a festa" e comecei a escrever as frases, assim, as coisas que eles falavam: "ah, professora, fulana ficou com ciclano". Aí, eu colocava os dois lá... "E aí, qual que é o sujeito aqui e qual que é o predicado?" Aí, eles ficaram ligados. Eu aproveitei isso do dia a dia deles, como vocês estão falando aí, que eles estão mais interessados no que está acontecendo no dia a dia, pra trabalhar. Então, assim, eles falaram: "Não sei quem veio com a 
mãe e com o pai...”. E eu fui pegando tudo isso e trabalhando frases do que tava acontecendo realmente, que eles tavam interessados em falar e trabalhando sujeito e predicado e tipos de sujeito. Pegando realmente o que tava acontecendo no dia a dia. Que eu querer brigar com eles para ensinar uma coisa e eles tavam querendo falar da festa, ia ficar difícil. Então eu aproveitei, dei a revisão, usando o que eles tavam falando. O que eles tinham vivenciado ali, o que eles queriam falar, que era bem interessante. (Marta) (informação verbal).

Todo mundo quis contar uma fofoca. E, dessa fofoca, nós aprendemos alguma coisa. Talvez... eu creio que tenham aprendido alguma coisa, porque chamou mais a atenção. Não sei se a atenção era saber o que tinha acontecido na festa ou realmente ali, na hora a explicação. Mas eu vi que eles prestaram mais atenção. Por isso, se tornou interessante: era uma coisa que eles... eles estavam falando. Eles que estavam discutindo, e eu só entrei ali mesmo com a gramática, né? De tá mostrando o sujeito, o predicado, os tipos de sujeito... E ficou engraçado. A gente começou a rir, porque, às vezes, eu perguntava: “Quem é o sujeito aqui?”. "Ih, professora, era aquele sujeito. Aquele!" "Mas, quem é aquele sujeito?” Então, assim, ficou uma aula engraçada. Foi interessante. Então, eu acho que dá pra gente trabalhar o dia a dia. (Marta) (informação verbal).

De acordo com a fala da professora Marta, uma boa aula é aquela em que@s estudantes prestam atenção ao que ela diz. Em outras palavras, para satisfazer o conceito que a professora tem do que seja uma boa aula de Língua Portuguesa, seus estudantes devem prestar toda atenção às suas explicações sobre o que é sujeito e predicado, responder aos exercícios em que lhes é exigido apenas identificar essas funções gramaticais e ainda ficarem muito felizes com isso. O vocabulário utilizado pela professora para se referir aos estudantes evidencia sua preocupação em agradá-los: "Eles ficaram muito eufóricos por causa da festa sábado”, “Aí, eles ficaram ligados", "[...] que eles estão mais interessados no que está acontecendo no dia a dia", "[...] e trabalhando frases do que tava acontecendo realmente, que eles tavam interessados em falar e trabalhando sujeito e predicado e tipos de sujeito", "[...] pegando realmente o que tava acontecendo no dia a dia". A professora posiciona-se como centro, em que o mais importante é @s estudantes seguirem a sua regência, como se ela estivesse dirigindo um espetáculo e, ao mesmo tempo, fosse a atriz principal, em que o estudo da língua é o que menos importa. Observe-se o emprego das palavras "só" e "mesmo", no trecho a seguir, com o sentido de minimizar o valor do estudo da gramática: "era uma coisa que eles, eles estavam falando, eles que estavam discutindo, e eu só entrei ali mesmo com a gramática, né?”

Essa situação deixa transparecer a contradição e o conflito por que passa a professora em sua busca por um ideal de aula de Língua Portuguesa interessante e "contextualizada",

\footnotetext{
9 O termo "contextualizada" foi empregado nos relatos das professoras para se referirem a um ensino da língua que faça sentido, principalmente para @s estudantes.
} 
em que o estudo das estruturas linguísticas seja instrumento para as práticas de letramento desenvolvidas em sala de aula. No entanto, isso não acontece porque as atividades de escrita das aulas não se relacionam com as práticas sociais. @s estudantes têm consciência disso, por isso, não valorizam as atividades de identificação de termos na oração. Com suas atitudes, a professora demonstra ignorar esse fato e procura justificar-se e valorizar seu papel social como professora usando a linguagem d@s estudantes como matéria-prima para a análise sintática descontextualizada, abstraída dos sentidos construídos nos textos.

Os professores de língua precisam conscientizar-se de que o centro das análises deve ser os gêneros que circulam nas diferentes esferas sociais, pois eles constituem a instância social em que a língua concretiza as práticas sociais. O texto escrito é um dos elementos do discurso e, por isso, não pode constituir o foco isolado do trabalho com a língua. Os professores de língua precisam constantemente fazer reflexão sobre as próprias práticas de ensino de gramática associada aos letramentos. Precisam compreender que os textos têm função social e constituem as práticas sociais, as quais atendem a demandas particulares; que a gramática do texto está relacionada ao contexto de situação segundo o qual os textos se configuram em termos de gênero, de estrutura textual e gramatical. Parece que a ausência dessa dimensão reflexiva leva as professoras a se sentirem perdidas no ensino dos letramentos e, em razão disso, ficam preocupadas com a sua imagem profissional, apresentando comportamentos de autovalorização para sustentarem o seu poder na interação com @s estudantes.

\section{Gêneros, textos e contextos}

Os gêneros não estão igualmente disponíveis e acessíveis a qualquer tempo e lugar porque as pessoas participam de práticas sociais específicas e não de todas. As práticas sociais articulam o discurso, as ações, as crenças, as atitudes e as histórias das pessoas nos eventos sociais que, por sua vez, são moldados pelas práticas sociais, as quais definem modos de agir. Por essa razão, é indicado que os professores do ensino fundamental, além de levarem para o espaço da sala de aula textos de gêneros que alcançam propósitos sociais diversos, focalizem a descrição do contexto de cultura e do contexto de situação dos textos que seus estudantes leem e escrevem para capacitarem-nos à leitura e à escrita dos textos que circulam nos diferentes espaços públicos e institucionais.

Nesta pesquisa, a professora Marta ( $6^{\mathrm{a}}$ série) desenvolveu algumas atividades de letramento em torno de textos, como carta de leitor, resenha crítica, notícia de jornal, poema e gêneros narrativos com base nas orientações fornecidas pelo livro didático, que apresenta as características estruturais dos gêneros. No entanto, nas atividades, não foram considerados o contexto cultural e o contexto de situação em que esses gêneros são criados ao solicitar que@s estudantes produzam esses textos. Analiso, em seguida, o modo como a professora Marta desenvolveu atividades de linguagem em torno da carta de leitor, porque ela apoiou-se unicamente no livro didático para analisar os outros textos mencionados em seu relato.

Na unidade sobre carta de leitor, o livro didático apresenta algumas cartas de leitor extraídas de jornais e de revistas e, em seguida, há algumas perguntas que induzem @ estudante a perceber as características desse gênero: 
a) A carta de leitor é um gênero textual que permite o diálogo dos leitores com o editor (a pessoa responsável pela revista ou pelo jornal) ou dos leitores entre si. Por meio dela, os leitores podem reclamar, solicitar, discutir, discordar, elogiar, etc.

b) Entre as cartas lidas, duas fazem elogios e, ao mesmo tempo, pedidos. Quais são elas?

c) E qual das cartas faz uma crítica à revista ou jornal? Que crítica é feita?

d) Que leitor dialoga com outro leitor? ${ }^{10}$

A última pergunta propõe que@s estudantes se reúnam em grupo para fazerem a síntese sobre as características de uma carta de leitor com base nas respostas às outras questões. Logo a seguir, há duas propostas para a produção da carta de leitor. Na primeira proposta, é apresentada uma reportagem sobre o hábito de ver televisão. Ao final dessa apresentação, vem o comando para o exercício:

Imagine que você tenha lido essa reportagem no jornal e queira se manifestar em relação a algo que lhe tenha chamado a atenção. Escreva então uma carta para o editor responsável pelo jornal ou à jornalista que assinou a matéria.

Você pode, por exemplo, manifestar-se em relação ao tema, comentando-o, relatando experiências próprias, etc. E também em relação ao enfoque dado ao tema, elogiando ou criticando o tratamento dispensado ao assunto pelo jornal ou pela jornalista que assina a reportagem ${ }^{11}$.

O texto é a expressão da linguagem em uso nas práticas sociais, da linguagem que é funcional (HALLIDAY; HASAN, 1991, por isso ocorre em dois contextos - o de situação e do de cultura. Ao apresentar exemplos de carta de leitor e mostrar as características da linguagem e da sua estrutura, o livro didático sugere uma relação entre o gênero e o contexto de situação desse gênero. Entretanto, a primeira proposta para criação de um texto simula o contexto de situação, porque @s estudantes precisam “imaginar” que leram a reportagem do jornal e recebem a orientação de que podem "manifestar-se em relação ao tema, comentando-o, relatando experiências próprias, etc.”, ou seja, eles podem fazer o que precisam fazer de fato para realizarem o gênero carta de leitor. O contexto de situação - que se refere ao que está acontecendo ou ao que aconteceu, à expressão de um ponto de vista e às semioses empregadas para a criação do texto - foi completamente desconsiderado. Portanto, ao propor a simulação

${ }^{10}$ CEREJA, W. R.; MAGALHÃES, T.C. Todos os textos: uma proposta de produção textual a partir de gêneros e projetos. São Paulo: Atual, 6 a série, p. 96.

${ }^{11}$ CEREJA, W. R.; MAGALHÃES, T.C. Todos os textos: uma proposta de produção textual a partir de gêneros e projetos. São Paulo: Atual, $6^{\text {a }}$ série p. 96. 
desse contexto para a criação de um texto, o livro didático conduz @s estudantes à produção de sequências de orações descontextualizadas de uma situação real de uso e não a um conjunto de significados unidos em torno de um propósito.

A segunda proposta para a criação de uma carta de leitor desenha uma sequência de atividades significativas para que@s estudantes escrevam um texto autêntico:

\begin{abstract}
Reúnam-se com seus colegas de grupo e escolham uma revista ou um jornal que queiram ler. Pode ser um jornal do bairro, da cidade ou do Estado; uma revista que trate de música, de esportes, de cinema, etc. Escolham nesse veículo de comunicação uma matéria que seja interessante e que, segundo o ponto de vista de vocês, mereça comentários, quer positivos, quer negativos, ou ainda as duas coisas.Escrevam então uma carta à revista ou jornal, comentando a matéria. ${ }^{12}$
\end{abstract}

Para criar textos que realizam gêneros, é essencial que @s estudantes compreendam o contexto social e cultural dos grupos sociais que usam a linguagem para agir e para interagir no mundo. Valer-se das variáveis do contexto de situação - campo, relações e modo - é um recurso útil para a descrição da variedade de linguagem que ocorre no contexto de situação que ancora a criação de qualquer texto. Explorando o campo de uma situação, professores e estudantes podem identificar palavras e estruturas para a construção de significados sobre a experiência desse contexto; explorando as relações sociais, podem identificar palavras e estruturas que constroem as relações interpessoais e a expressão dos pontos de vista e assim construir significados interpessoais; explorando o modo do discurso, podem identificar palavras e estruturas que organizam os significados experienciais e interpessoais em um texto oral, escrito ou visual organizado quanto ao fluxo das informações que veicula na elaboração dos significados textuais e adequado ao contexto de situação e ao contexto de cultura.

No estudo sobre a notícia, a professora basicamente seguiu as orientações do livro didático, que apresenta os elementos da estrutura do gênero e as características da linguagem, induzindo@s estudantes a identificá-los, estimulados pelas perguntas de um questionário breve. Na última questão, @s estudantes são solicitados a sintetizarem o que aprenderam sobre a notícia. Na sequência, o livro propõe a elaboração de uma notícia com base na leitura de jornais e de revistas e na conversa com pais, com professores, com colegas e com vizinhos sobre o assunto escolhido; e, depois, fornece orientações sobre as características da linguagem que@s estudantes devem usar.

A proposta do livro didático ignora as práticas sociais que envolvem a produção de uma notícia. No dia a dia, os jornalistas vão atrás dos fatos no momento em que acontecem e das informações relativas ao tópico da notícia, vivenciando-os antes de redigirem o texto que será publicado em algum jornal ou revista. Entretanto, @s estudantes devem criar textos tendo

${ }^{12}$ CEREJA, W. R.; MAGALHÃES, T.C. Todos os textos: uma proposta de produção textual a partir de gêneros e projetos. São Paulo: Atual, $6^{\text {a }}$ série, 2011, p. 96. 
como referencial apenas a estrutura do gênero, o modo de utilizar a linguagem e a situação na qual aquele texto ocorre. A dimensão do contexto de situação, que remete às práticas sociais, para a elaboração do texto é obscurecida:

Ao escrever sua notícia, siga estas instruções:

a) Faça um planejamento. Leia jornais e revistas, depois, converse com seus pais, professores, colegas e vizinhos sobre o assunto escolhido, procurando obter o maior número possível de informações.

b) Tenha em mente o leitor de seu texto: escreva com simplicidade, na ordem direta (sujeito, verbo e complementos); sempre que possível, empregue uma palavra em vez de duas ou mais; use frases curtas, com duas ou três linhas no máximo, e parágrafos com poucas frases; empregue o vocabulário comum; evite palavras difíceis, termos coloquiais, gírias, superlativos e adjetivos desnecessários; procure responder às perguntas que um leitor gostaria de fazer: o quê?, quem?, quando?, onde?, como?, por quê?.

As pessoas produzem textos para fazerem coisas no processo da construção dos significados nos eventos sociais. Assim sendo, uma notícia é um texto cujos contextos de cultura e de situação requerem que o jornalista vivencie os fatos antes de relatá-los, além de obter informações com as pessoas que participaram do acontecimento para redigi-la em linguagem apropriada. Em outras palavras, é preciso reunir os elementos do contexto de cultura e de situação para criar textos atrelados a situações reais.

A unidade do livro didático sobre a caracterização e a produção de uma notícia ignora a perspectiva segundo a qual é representada a realidade retratada no texto. Os gêneros são modos de agir e de interagir discursivamente, nos quais os discursos constituem modos de representação do mundo material, social e mental. Como elementos das ordens de discurso nas práticas sociais, os gêneros figuram nos textos em termos de ação, de representação e de identificação (FAIRCLOUGH, 2003, p. 28). No gênero notícia, além da análise dos contextos de cultura e de situação e da estrutura do gênero, há que se examinar de qual perspectiva a realidade é representada e de que maneira diferentes discursos estruturam o mundo. Olhar os textos da perspectiva da sua representação implica verificar que elementos dos eventos sociais estão incluídos ou excluídos, em qual extensão e qual a proeminência dos elementos incluídos. Esses elementos referem-se às atividades; às pessoas e suas crenças, seus desejos, seus valores, suas histórias, suas relações institucionais e interpessoais; aos meios, ao tempo e ao espaço, às línguas e a outros tipos de semioses (FAIRCLOUGH, 2003, p. 136).

Os textos também representam as identidades de seus autores por meio de processos textuais de identificação, como a modalidade e a avaliação, isto é, o modo como o falante faz julgamentos sobre as probabilidades e as obrigações envolvidas naquilo que está dizendo. No estudo do gênero notícia, cabe verificar como a modalidade sinaliza a factualidade, os graus 
de certeza ou de dúvida, de generalização, de possibilidade, de necessidade, de permissão e de obrigação. Como os repórteres expressam sua avaliação, seus valores e julgamentos em relação às situações narradas, às pessoas e às coisas apresentadas como desejáveis e indesejáveis, boas e ruins, nas quais acreditamos ou não (FAIRCLOUGH, 2003, p. 165-173).

As propostas do livro didático para a elaboração de uma carta de leitor não levam em consideração a perspectiva interpessoal, que é típica na produção textual desse gênero. Observemos as instruções que o livro dá aos estudantes:

Sigam essas instruções:

a) Anotem e discutam os aspectos da matéria merecedores de comentários, bem como os argumentos que vão fundamentar o ponto de vista de vocês por que gostaram ou por que não gostaram, etc.

b) Redijam o texto atentos à estrutura desse tipo de carta. Deixem claro, desde o início, qual é a data do jornal ou o número da revista em que foi publicada a matéria sobre a qual estão opinando. Identifiquem a matéria pelo título e/ ou pelo nome do jornalista que a assina.

c) Apresentem suas opiniões de forma firme, mas educada, sempre fundamentando com bons argumentos. Se estiverem fazendo uma crítica negativa não deixem de elogiar os pontos positivos e vice-versa.

d) Tenham em vista o leitor de sua carta, que será primeiramente o jornalista ou o editor e, se ela for publicada, o leitor do jornal ou revista - criança, jovem ou adulto. Procure adequar a linguagem ao perfil desses leitores.

O item c) das instruções contraria o contexto de cultura e de situação na criação de textos do gênero carta de leitor. As pessoas que enviam essas cartas a jornais e a revistas fazem críticas a alguma matéria publicada nas últimas edições e posicionam-se a favor ou contra, apresentando sua avaliação, seus julgamentos, seus valores e suas crenças sobre reportagens ou notícias. O item d) parece-me inadequado, pois, como @ estudante de 6. ${ }^{\mathrm{a}}$ Série, cujo modo de usar a linguagem é próprio da sua idade, pode utilizar uma linguagem que não pratica, uma vez que não vivencia as práticas sociais que demandam um gênero direcionado a adultos? Isso, porém, não significa que @s estudantes não sejam capazes de refletir sobre essa linguagem e mesmo de exercitarem o seu uso.

Tudo isso ultrapassa o simples reconhecimento dos elementos constituintes do gênero, que é relacionado à prática de letramento em foco nas aulas. A prática de textos nas aulas de Língua Portuguesa constitui uma representação de eventos sociais que passam a ser recontextualizados quando@s estudantes simulam a prática de gêneros em situações cujas práticas serão imaginadas. A recontextualização envolve diferenças no modo como um evento social é representado em diferentes redes de práticas sociais e diferentes gêneros, afetando a representação abstrata e concreta dos eventos sociais, o modo como são avaliados, explicados, legitimados e em que ordem são apresentados. 


\section{Considerações finais}

Os gêneros são modos abstratos, reconhecidos socialmente, de usar a língua. Baseiamse na suposição de que os aspectos linguísticos de um grupo similar de textos dependem do contexto social em que foram criados e são usados, que aqueles aspectos podem ser descritos de modo a relacionar um texto a outros parecidos e às escolhas e restrições dos seus produtores. A língua é constitutiva das realidades sociais, uma vez que é por meio do uso recorrente de formas convencionais que os indivíduos desenvolvem relações interpessoais, participam de grupos sociais e realizam coisas. As relações interpessoais estão no centro do uso da língua, significando que cada texto bem-sucedido revelará a consciência do escritor sobre o contexto sócio-histórico da sua criação e os leitores que fazem parte desse contexto. Os gêneros, portanto, são

os efeitos da ação dos agentes sociais individuais, que agem tanto nos limites da sua história quanto das restrições de contextos particulares, e com um conhecimento dos tipos genéricos existentes (KRESS, 1989, p. 10).

De acordo com Hyland (2003), o ensino de língua com base nos gêneros repousa na ideia de que os letramentos são recursos da comunidade que se realizam nas relações sociais, são situados e múltiplos e posicionam-se em relação às instituições sociais e às relações de poder que os sustentam. Dito de outra forma, a escrita - usada de muitos modos nos diversos contextos sociais - e os gêneros estão associados a usos que regulam o acesso das pessoas a grupos sociais que possuem prestígio e influência.

Essa questão do acesso e da produção de textos valorizados socialmente é central às noções de poder e de controle na sociedade moderna. Isso implica que professoras/es de Língua Portuguesa precisam refletir sobre os gêneros que devem ser ensinados porque o ensino de determinados gêneros é um meio de levar@s estudantes a obterem acesso aos modos de comunicação que são investidos de capital cultural ${ }^{13}$ nas comunidades profissionais, acadêmicas e sociais. A escolha estratégica dos gêneros levados para as aulas pode instrumentalizar@s estudantes para que participem de novos domínios sociodiscursivos.

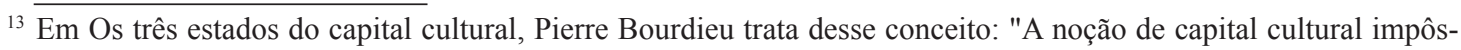
se, primeiramente, como uma hipótese indispensável para dar conta da desigualdade de desempenho escolar de crianças provenientes das diferentes classes sociais" (BOURDIEU, 1998, p. 73). Em outras palavras, "[...] na realidade, cada família transmite a seus filhos, mais por vias indiretas que diretas, um certo capital cultural e um certo ethos, sistema de valores implícitos e profundamente interiorizados, que contribui para definir, entre outras coisas, as atitudes em face do capital cultural e da instituição escolar" (BOURDIEU, 1998, p. 42). Isto é, a posse de certo capital cultural e de um ethos familiar predisposto a valorizar e a incentivar o conhecimento escolar seriam importantes elementos para se alcançar um sucesso acadêmico. Neste sentido, crianças mais abastadas e com maior acesso aos bens culturais seriam aquelas que teriam as maiores chances de obter um bom desempenho escolar (SETTON, 2005). 
$\mathrm{Na}$ escola, as práticas de letramento baseadas nos gêneros podem ser instrumentos para a construção coletiva do conhecimento. Quanto mais for possível definir as dimensões ensináveis dos gêneros, melhor eles serão apreendidos pel@s estudantes. O ensino de Língua Portuguesa nas turmas de ensino fundamental que participaram desta pesquisa baseou-se em um número bastante reduzido de gêneros presentes nas práticas de letramento das aulas, nas quais textos foram lidos. Muitos exercícios gramaticais foram feitos de forma descontextualizada e, portanto, sem sentido. Isso significa que, no contexto cultural das aulas observadas, professoras e estudantes pouco leram e escreveram e, quando o fizeram, as atividades de letramento não tiveram um propósito social. Os textos foram trazidos para as aulas para transformarem-se apenas em objetos de leitura, em realização de exercícios gramaticais e em interpretação de texto.

A fim de mudar sua prática docente para o ensino significativo de letramentos, as professoras precisam compreender que os textos concretizam gêneros, que fazem parte de atividades sociais concretas. Os gêneros medeiam diferentes padrões de interação e têm determinado formato em razão do papel que exercem nas instituições sociais. Nesse sentido, é recomendado que@s professoras/es de Língua Portuguesa no ensino fundamental façam reflexão sobre que tipos de textos e de gêneros seus estudantes estão lendo e escrevendo e quais os seus propósitos sociais. Quando se apropriam dos gêneros, as pessoas desenvolvem os tipos de conhecimento especializado (BAZERMAN, 2005, p.67) que as habilitam a participarem ativamente da sociedade.

Analisar criticamente os diversos letramentos, fundamentando-se na perspectiva social do letramento (STREET 1995; BARTON 1994; BARTON; HAMILTON 1998; BARTON; IVANIC, 1991; BARTON; HAMILTON; IVANIC, 2000), capacita @s estudantes a identificarem os sentidos além do texto, bem como os interesses subjacentes aos significados. Entender os letramentos como elementos das práticas sociais na análise dos gêneros implica verificar que papel o letramento desempenha nas práticas institucionais e as quais propósitos está servindo. O letramento constitui práticas que se impõem pelo uso dos gêneros do poder, cujo domínio possibilita o acesso das pessoas a conhecimentos especializados e a serviços, permitindo que elas se relacionem com instituições que nem sempre lhes são familiares.

A abordagem dos gêneros como propósito social (EGGINS; MARTIN, 2000; EGGINS, 2004), associada à perspectiva sistêmico-funcional para a análise de textos (HALLIDAY; HASAN, 1991; HALLIDAY; MATTHIESSEN, 2004), propicia a professores e a estudantes a consciência de que as estruturas linguísticas dos textos relacionam-se ao contexto cultural e social em que foram criados e em que são usados. Essas abordagens teóricas enfatizam o desenvolvimento do conhecimento sobre o controle exercido por textos que constituem as práticas de letramento dominantes nas diferentes instituições (STREET, 1984, 1995). Entretanto, a transmissão descontextualizada de tipos textuais e de seus aspectos gramaticais não conduz a uma avaliação crítica das práticas de letramento e dos gêneros a elas associados no contexto das aulas de Língua Portuguesa. Ao contrário, pode estar a serviço da reprodução não crítica das práticas de letramento autônomo, criticadas por Street (1995).

As pedagogias baseadas nos gêneros (HYLAND, 2003, p. 25) supõem que o domínio de tipos textuais "poderosos" pode levar @s estudantes ao desenvolvimento intelectual e cognitivo, à realização profissional, ao acesso aos bens culturais da humanidade e à mobilidade social. 
Nessa linha de raciocínio, o modelo freireano teoriza o "empoderamento" como abertura aos espaços sociais para as pessoas marginalizadas, a fim de que articulem seus interesses nas instituições baseadas no controle da tecnologia dos textos escritos (FREIRE 1983).

De modo geral, os professores que focalizam as regras e a correção gramatical desejam que seus estudantes aprendam a usar a língua culta. Essa forma de olhar para a linguagem obscurece a diversidade do uso da linguagem, além de considerar todos os outros usos como não padrão. Em vez de conceber a gramática em termos de regras que prescrevem o modo como a linguagem é estruturada, a abordagem sistêmico-funcional pensa a gramática como um modo de descrever padrões da linguagem e as funções que esses padrões desempenham, estudando a gramática de textos nos contextos de cultura e de situação que os demandam.

Esta pesquisa buscou conhecer como os gêneros relacionam-se às práticas de letramento nas aulas de Língua Portuguesa e ao ensino da gramática. As entrevistas cumpriram a função de criar oportunidade para as professoras falarem de suas práticas docentes e de suas inquietações. As observações das aulas foram significativas para que eu pudesse vivenciar a experiência de várias aulas de Língua Portuguesa, de $5^{\mathrm{a}}$ a $8^{\mathrm{a}}$ série. As informações obtidas por meio desses métodos de coleta de dados permitiram-me compreender que ensinar Língua Portuguesa no ensino fundamental ainda é um desafio, porque as professoras não dispõem de recursos teóricos e metodológicos que lhes forneçam sustentação para o ensino dos letramentos.

Uma pedagogia de ensino de letramentos demandados por diferentes práticas sociais, associada ao uso de gêneros, instrumentaliza discursiva e gramaticalmente professores e estudantes para que reconheçam a diversidade do contexto sócio-histórico que envolve os textos, conforme as práticas sociais que os demandam. Os professores de Língua Portuguesa precisam reconhecer as convenções dos diferentes gêneros sem, no entanto, serem prescritivos e normativos. Isso pode ocorrer quando apresentam aos seus alunos listas sobre as propriedades dos diferentes gêneros. É importante compreenderem que modos particulares de usar a linguagem são modos de estruturar o conhecimento e as relações interpessoais. Quando as pessoas usam a linguagem, estão se valendo dos recursos de uma língua - o português brasileiro, por exemplo - e fazem isso sempre por meio dos gêneros, que são cultural e socialmente construídos.

\section{Referências}

BAKHTIN, M. Estética da criação verbal. Trad. M.E.G. Pereira. ed., São Paulo, Martins Fontes, 2000.

BARTON, D. Literacy: an introduction to the ecology of written language. Oxford, Cambridge: Blackwell Publishers, 1994.

BARTON, D. ; HAMILTON, M. Local literacies. Londres and Nova Iorque: Routledge, 1998.

BARTON, D.; HAMILTON, M.; IVANIC, R. (Orgs.). Situated literacies: reading and writing in context. Londres, New York: Routledge, 2000. 
BARTON, D. \& IVANIC, R. Writing in the community. Newbury Park, Londres, Nova Delhi: Sage Publications, 1991.

BARTON, D; HAMILTON, M. Local literacies. Londres and Nova Iorque: Routledge, 1998.

BAZERMAN, C. Gêneros textuais, tipificação e interação. Ângela Paiva Dionísio, Judith Chambliss Hoffnagel, (Orgs.); tradução e adaptação de Judith Chambliss Hoffnagel; revisão técnica Ana Regina Vieira... [et al.]. - São Paulo: Cortez, 2005.

CEREJA, W. R.; MAGALHÃES, T.C. Todos os textos: uma proposta de produção textual a partir de gêneros e projetos. São Paulo: Atual, 6ª série, 2011.

CHOULIARAKI, L.; FAIRCLOUGH, N. Discourse in late modernity: rethinking critical discourse analysis. Edinburgh: Edingurgh University Press, 1999.

EGGINS, S. An introduction to systemic functional linguistics. 2. ed., New York, Londres: Continuum, 2004.

EGGINS, S.; Martin, J.R. Géneros y registros del discurso. In: VAN DIJK, T.A. El discurso como estructura y proceso. Barcelona: Gedisa, 2000.

FAIRCLOUGH, N. Analysing discourse: textual analysis for social research. Londres \& Nova Iorque: Routledge, 2003.

. Discurso e mudança social. MAGALHÃES, Izabel (Coord. trad., rev. e pref.). Brasília: Editora Universidade de Brasília, 1992/2001.

. Critical discourse analysis. Londres and Nova Iorque: Longman, 1995.

. Language and power. Londres e Nova Iorque: Longman, 1989.

HALLIDAY, M.A.K.; HASAN, R. Language, context, and text: aspects of language in a social-semiotic perspective. Oxford University Press, 1991.

HALLIDAY, M.A.K. e MATTHIESSEN, C.M.I.M. An introduction to functional grammar. 3. ed., Oxford, Londres: Arnold, 2004.

HALLIDAY, M.A.K. e HASAN, R. Language, context, and text: aspects of language in a socialsemiotic perspective. Oxford University Press, 1991.

Hyland, K. Genre-bases pedagogies: a social response to process. Journal of Second Language Writing, 12, 2003.

NEVES, M.H.M. Que gramática estudar na escola? 3. ed. São Paulo: Contexto, 2006.

PAGANO, A. Gêneros híbridos. In: C. Magalhães, (Org.) Reflexões sobre a análise crítica do discurso, 
Belo Horizonte: Faculdade de Letras, UFMG, 2001.

STREET, B. Literacy events and literacy practices: theory and practice in the New Literacy Studies. In Jones, M. M. e Jones, K. (Orgs.) Multilingual literacies: reading and writing different worlds. John Benjamins Publishing Company, Amsterdam/Philadelphia, 2000.

STREET, B. Social literacies: critical approaches to literacy in development, ethnography and education. London and New York: Longman, 1995.

. (Org.). Cross-cultural approaches to literacy. Cambridge: Cambridge University Press, 1993.

. Literacy in theory and practice. Cambridge: Cambridge University Press, 1984. 
